
\title{
Research Suare \\ Determinants of Perinatal Mortality in Tercha General Hospital, Southern Ethiopia; Facility Based Case Control Study.
}

Firehiwot Tebeje ( $\nabla$ firetebeje@gmail.com )

Jabatan Kesihatan Wilayah Persekutuan Kuala Lumpur dan Putrajaya https://orcid.org/0000-00020231-7824

\section{Animut Addis}

Jimma University College of Public Health and Medical Sciences

\section{Muktar Basher}

Jimma University College of Natural Sciences

\section{Chernet Hialu}

Jimma University College of Public Health and Medical Sciences

Research article

Keywords: Perinatal Mortality; Determinants; Tercha General Hospital

Posted Date: September 27th, 2019

DOI: https://doi.org/10.21203/rs.2.15205/v1

License: (9) This work is licensed under a Creative Commons Attribution 4.0 International License. Read Full License 


\section{Abstract}

Background: Ethiopia meets the target millennium development goal 4 on child survival three years ahead of time. However, there were high perinatal deaths in the country and the reduction was not impressive. Identifying determinants and implement evidence based interventions is crucial to reduce perinatal death. However, there were no clear evidences on determinants of perinatal mortality in Tercha General Hospital.

Objective: To assess determinants of perinatal mortality in Tercha general hospital, Southern Ethiopia, January 1, 2014 and December 30, 2017.

Method: An unmatched case control study using secondary data as a source of information was conducted in Tercha general hospital. Cases were stillbirths and early neonatal deaths. Controls were those newborns live till 7th days. Randomly selected 366 (183 cases and 183 controls) study subjects were constituted for this study. The data were collected from March 1-20/2018. Epi-Data version 3.1 and SPSS Version 23 were used for data entry and analysis, respectively. Descriptive statistics were used to describe the study population in relation to study variables. Logistic regressions were employed to identify determinants of perinatal death.

Results: In multivariable logistic analysis, rural in residence of the mother [AOR=1.82; 95\% Cl:(1.04-3.19)], ANC booking [AOR=0.47; 95\% Cl:(0.27,0.83)], prolonged labour [AOR=2.75; 95\% Cl: (1.58-4.78)], low birth weight [AOR=1.78; $95 \% \mathrm{Cl}(1.06-2.97)]$, presence of obstetrics complication [AOR=2.15; 95\%Cl: (1.28-3.62)], using partograph [AOR=0.5; 95\%Cl: 0.25-0.9]. Using safe child birth checklist [AOR=0.52; 95\%Cl: $0.30-$ $0.91]$, and coming with referral [(AOR=2.69; $95 \% \mathrm{Cl}$ : (1.51-4.8)] were significantly associated with perinatal mortality.

Conclusion and Recommendation: Being rural in residence, coming with referral, low birth weight, prolonged labour and presence of obstetric complication were associated with elevated the risk of perinatal mortality, and antenatal care booking, using partograph and using safe childbirthchecklist were associated with reduced risk of perinatal mortality. We therefore, recommend strengthening maternal health and newborn care servicesby taking into account these factors to reduce perinatal death.

\section{Introduction}

Perinatal mortality, as defined by World Health Organization (WHO), is total number of deaths in the perinatal period. This includes still birth (death of fetus after 28 weeks of gestation or above 1000gram birth weight) and early neonatal death (END) i.e. death of live new-born before the age of 7 completed days $(1,2)$. While the WHO, the International Stillbirth Alliance and some developed countries utilize 22 weeks as their age of viability and a loss at that gestational age reported as perinatal mortality(3). In countries like Ethiopia, viability age greater than 28 week is considered for the report (4). 
Newborns are at most risk of dying in their first week of birth, and globally three-quarters of neonatal deaths occur in the first week of life (5). Stillbirths account for over half of all perinatal deaths. One third of stillbirths takes place during delivery, and is largely avoidable. Intra-partum deaths (i.e. those occurring during delivery) are closely linked to place of care at delivery $(3,6)$.

Every year, nearly 7 million perinatal deaths occur across the globe (3.5 million stillbirths and 4 million neonatal deaths), which is higher than the combined annual all age level deaths due to Acquired Immune Deficiencies Syndrome(AIDS) (2.1 million), tuberculosis (1.6 million) and malaria (1.3 million) $(3,7,8)$.

Perinatal mortality is at an unacceptably high level in low and middle income countries, about $99 \%$ of these perinatal deaths occur in this country (9). In addition to this, the true mortality rate is under estimated in low and middle income countries where vital registration is not available(10).In Sub Saharan Africa approximately 30 million women become pregnant in a year. Of those, about 1 million deliveries are still birth; at least 1 million babies die in their first month of life and 0.5 million die on the first day of life (11).

Ethiopia like other sub-Saharan countries has a high perinatal mortality. According to WHO report, PMR of Ethiopia in 2004 was 128,000 total deaths (34,000 still births and 94,000 early neonatal deaths)(12). According to Ethiopian Demographic and Health survey (EDHS-2016) perinatal mortality rate was 33 deaths per 1,000 pregnancies $(13,14)$. The overall perinatal mortality reported from ten hospital based studies in Ethiopia was in the range of 66 to 124 per 1000 births. The report of the large scale community based perinatal mortality was also in the range of 37 to 52 per 1000 births (7).

Studies conducted in Ethiopia showed that perinatal mortality was associated with maternal socio demographic status like maternal age, occupation, birth interval, occupation $(13,15,16)$. Maternal obstetrics and medical factors history such as Antenatal Care (ANC), Human immune deficiency Virus (HIV) status, history of obstetrics complications, parity, mode of delivery and neonatal related factors like fetal presentation, birth weight, and sex were variables which associated with perinatal mortality (27-31).

Southern Nations Nationalities Peoples and Representative (SNNPR), region is one of the regional states in Ethiopia which had perinatal mortality rate of 26 deaths per 1,000 pregnancies in EDHS 2016 report(13). Dawro zone is one of the largest populated zones in the region, with low health services coverage, institutional delivery and antenatal coverage (19). A study conducted at Tercha General Hospital (TGH) showed, perinatal mortality among the group of mothers undergone a major obstetrics intervention (Cesarean section(C/S), laparotomy for repair of uterus, hysterectomy, and destructive operation) were 258 per 1,000 live births (20).

Identifying determinants and implement evidence based interventions is crucial to reduce perinatal death. However, up to the knowledge of principal investigator while searching different literatures, there was no study done to assess determinants of perinatal mortality in TGH. Therefore, this study helps to assess determinants of perinatal mortality among hospital deliveries that will help to improve all concerned 
bodies understanding on the factors associated to perinatal mortality and serves as an important tool for planning and resource allocation that aimed to improving newborns survival.

\section{Materials And Methods}

\section{Study setting and Period}

The study was conducted at Tercah General Hospital which is found Tarcha town, SNNPR. Tercha town is located at south west of Ethiopia, $517 \mathrm{Kms}$ away from Addis Ababa and $285 \mathrm{Kms}$ away from Hawassa (the capital city of SNNPR). The Hospital have 120 beds. There are 40 beds in the maternity ward, 4 labor beds and 3 delivery Koch. There is also neonatal intensive care unit with kangaroo mother care room (equipped with 4 beds). There are 150 clinical 87 supportive staff members (19). The study was conducted from March 1-20/2018

Study Design: Hospital based unmatched Case Control Study Design was employed.

Population:Cases were randomly selected perinatal deaths that were attended in TGH from January 1 , 2014 and December 30, 2017 and controls were randomly selected live births that were attended in TGH and alive up to 7 days in the same year with cases.

\section{Sample size determination and Sampling technique}

The required sample size was calculated by the statistical program of Epi-info stat Calc tool by considering different factors strongly associated with perinatal mortality from previous study conducted in Addis Ababa:birth interval <2 years, congenital anomalies, $\mathrm{C} / \mathrm{S}$ delivery, $\mathrm{Hg}$ level $<11 \mathrm{gm} / \mathrm{dl}$ and partograph use (12). Based on the assumption of case to control ratio of 1:1,95\% confidence level, Power of $80 \%$ percentage of controls exposed (Hemoglobin level $<11 \mathrm{gm} / \mathrm{dl}$ ) $8 \%$ and odds ratio of 2.6 , the total sample size for this study became 366 (183 case and 183 controls). All perinatal cases and controls identification number (card number) in between January 1, 2014 and December 30, 2017 were taken from delivery room and neonatal intensive care unit registration log book then the required sample size were selected by using simple random sampling technique with computer generated random number.

\section{Variables:}

Dependent Variable; Perinatal Mortality

\section{Independent variables}


Maternal Socio demographic factors: Age, marital status, residency, occupational status, and educational status

Maternal obstetrics history related factors: Parity, birth interval, ANC booking, Tetanus Toxoid(TT) vaccination status, gestational age, mode of delivery, history of abortion, history of previous perinatal mortality, duration of labour, and history of obstetrics complications

Maternal medical illness Factors: HIV status, Venereal Disease Research Laboratory (VDRL) test result, hepatitis B test result, hemoglobin level ( $\mathrm{gm} / \mathrm{dl})$, history of chronic Disease.

Newborn related factors: presentation, sex, weight, congenital anomaly.

Health care related factors: partograph use, use safe child birth checklist, and coming with referral

\section{Data collection tool}

The tools were developed from different literatures $(17,22,26,27)$ and contained five different Section. Section one: maternal Socio demographic factors; it contains five items, Section two: maternal obstetrics factors: it contains eight items, Section three: maternal medical Factors: it contains six items, Section four: Newborn related factors: it contains seven items, Section five: Health care related factors: it contains three items

\section{Data Collection Procedures}

During data collection, delivery registry books were reviewed and selection of cases and controls was done from the registration books then the cards of both the selected cases and controls were traced from the archive (card room) using card numbers found in the registration book. For stillbirths and live births maternal cards were reviewed; and for early neonates death neonates card were assessed, if missing data in the early neonates card happened, their maternal cards were trace from the card room and complete it.

\section{Data quality Assurance}

Prior to data collection careful modification of the data collection tool were made. The tool was pre-tested (using $5 \%$ of sample size $=18$ ) at TGH by using the source population (November- December 2013). Data collectors and supervisors were trained for 3 days. The tool also commented by two Epidemiology experts. Daily supervision of the data collection procedure was made.

\section{Data processing and analysis}


Before data entry data were cheeked for completeness, then data were coded and entered into Epi-Data version 3.1 then data were exported to Statistical package for social science (SPSS) Version 23 for checking the missing values, outliers, and analysis. Descriptive analysis was made to describe the study populations in relation to study variables.

First, bivariate logistic regression was done to select candidate variables for multi variable logistic regression. All variables having P-value $\leq 0.25$ during bivariate analysis were considered as candidates for the multi variable logistic regression. After the multi variable logistic regression analysis variables having $p$-values $<0.05$ was considered as having statistical significant association with prenatal mortality. Model fitness was checked by Hosmer \& Lemeshow goodness of test ( $p$-value $=0.542$ ). The degree of association between independent and dependent variables was assessed by using Adjusted Odds Ratio (AOR) with 95\% Cl. Finally, the data were presented by tables and frequencies.

\section{Ethical Clearance}

Ethical clearance was obtained from Institutional Review Board (IRB) of Jimma University, Faculty of Public Health. Permission was obtained from Tercha General Hospital and consent was taken from the manager. Names and other personal information which can violate the confidentiality of the study subjects were not taken. Any information have been kept confidentially.

\section{Results}

\section{Socio-demographic characteristics of the respondents}

The total of 366 study subjects (183 cases and 183 controls) were included in this study with $100 \%$ response rate. The mean age of mothers for cases and controls was $27.7 \pm 6.2$ and $26.4 \pm 5.9$ years, respectively. The highest proportion of mothers of cases $135(73.7 \%)$ were in the age group 20-35 years. Majority of cases 153 (83.6\%) were born from married mother. One third of mother of controls $66(36.07 \%)$ were at primary school level while $21(11.48 \%)$ of the controls were diploma and above. Most of mothers of cases (79.2\%), were from rural area while $106(57.9 \%)$ of the controls were from rural areas (Table 1).

\section{Maternal Obstetrics Characteristics}

Primipara mothers were higher in the control group than the cases. The proportion of mothers had antenatal care follow up at least one times in the current pregnancy in cases were 118(64.48\%) and in controls were $146(79.78 \%)$. The proportion of mothers who received at least two doses of TT vaccination in cases were $117(63.93 \%)$ and in controls were $143(78.14 \%)$. Regarding mode of delivery, $58(31.69 \%)$ of 
the cases and $30(16.39 \%)$ of the controls were delivered by cesarean section. Thirty three $(18.03 \%)$ of cases and $17(9.29 \%)$ of controls had previous history perinatal mortality. With regard to the durations of labor, relatively long duration of labor was observed among cases. The median duration of labour in the cases and the controls group was 12 and 9 hours, respectively. One hundred three (56.28\%) of the cases were born from mothers having at least one type of obstetric complication while it was only $51(27.87 \%)$ in the control group. Among obstetrics complications, newborn with antepartum hemorrhage responsible for $28(15.3 \%)$ of perinatal death, PROM responsible for $24(13.1 \%)$ of perinatal deaths (Table 2 ).

\section{Maternal medical and Neonatal related factors}

Regarding to maternal medical factors, 345 screened for HIV of which 340 (92.8\%) were non-reactive and $4(1.09 \%)$ were reactive among reactive mothers four of them were mothers of cases. Ninety seven percent of mothers were non-reactive for VDRL test. Majority of participants (84.6\%) were none reactive and $0.8 \%$ were positive for hepatitis B surface antigen testing. Forty-three mothers of $(23.5 \%)$ cases and $16(8.7 \%)$ controls hemoglobin level were less than $11 \mathrm{gm} / \mathrm{dl}$. Thirty one $(16.9 \%)$ of cases and $14(7.65 \%)$ of controls of were born from mothers who were diagnosed at least one type of medical illnesses in the current pregnancy. Concerning to neonatal related factors, One hundred seven (58.47\%) cases and $136(74.3 \%)$ controls mode of delivery were vertex in fetal presentation. The proportion of congenital anomaly in was higher in cases (3.83\%) than controls (1.69\%). The proportion of low birth weight (Wt $<2500 \mathrm{gm}$ ) cases and controls were 78(42.62\%) and 55(30.05\%), respectively (Table 3).

\section{Organizational related factors}

The proportion of partograph use was high in controls (88.5\%) than cases $(69.9 \%)$. Safe childhood checklist was used in $138(75.4 \%$ ) controls and $102(55.7 \%)$ cases. Among those $51(58 \%)$ of mothers had at least one obstetrics complication. Seventy two (39.3\%) of mothers of cases were referred from other health institution with referral paper (Table 4)

\section{Determinants of perinatal mortality.}

Binary logistic regression was done to assess the association of perinatal mortality with different characteristics. After multi variable analysis; place of residence [AOR $=1.82 ; 95 \% \mathrm{Cl}:(1.04-3.19) ; \mathrm{p}$-value $=$ $0.035]$,ANC booking[AOR $=0.47 ; 95 \% \mathrm{Cl}$ : $(0.27,0.83)$; $\mathrm{p}$-value<0.001],prolonged labor $[\mathrm{AOR}=2.75 ; 95 \% \mathrm{Cl}$ : (1.58-4.78), obstetrics complication [AOR $=2.15 ; 95 \% \mathrm{Cl}$ : $(1.28-3.62) ; \mathrm{p}$-value $=0.004]$, birth weight [AOR $=1.78 ; 95 \% \mathrm{Cl}(1.06-2.97) \mathrm{p}$-value $=0.029]$. Similarly, use of partograph $[\mathrm{AOR}=0.5 ; 95 \% \mathrm{Cl}$ : $(0.25-0.9) ; \mathrm{p}-$ value $=0.025]$ use of safe childbirth checklist $[A O R=0.52 ; 95 \% \mathrm{Cl}:(0.30-0.91) ; p$-value $=0.024]$ and coming with referral [(AOR $=2.69 ; 95 \% \mathrm{Cl}:(1.51-4.8) ; \mathrm{p}$-value $=0.001]$ were found to be independent determinants of perinatal mortality (Table 5$)$. 


\section{Discussion}

Mothers who were rural in residence were two times more likely to have perinatal mortality compared to those mother who were urban in residence [AOR $=1.82 ; 95 \% \mathrm{Cl}:(1.04-3.19), p=0.035]$. This finding is consistent with the study conducted in Jimma university referral hospital and showed that mothers who live outside Jimma is more likely to have perinatal death [AOR $=2.861 ; 95 \% \mathrm{Cl}: 1.99-3.33]$ (21). This might be due to the fact that mothers live in rural area have exposure to lack of awareness, inaccessible healthy facility, poor transport access, or probably due to their big delay in health care seeking behavior; this all lead to obstetrics complications and increase the risk of perinatal loss.

In the present study, among socio demographic variables maternal level of education, age, occupational status, and marital status were not associated with perinatal mortality. This finding is similar with the results of other studies in Ethiopia $(22,27)$ and study in Sudan $(23)$.

Mothers with ANC booked were $53 \%$ less likely to have perinatal death than those who were un-booked $[(A O R=0.47 ; 95 \% \mathrm{Cl}:(0.27,0.83)), p<0.001]$. Our finding is comparable with the result of other studies in Ethiopia $(25,27,28)$ and developing countries in Africa [AOR $=0.3 ; 95 \% \mathrm{Cl}(0.1-0.6) ; \mathrm{p}=0.002](23)$ that showed that having ANC follow up is a protective factor for perinatal mortality. This might be due those women's who attended ANC had more opportunity to prevent, identify, and treat pregnancy related conditions as well as help a woman approach pregnancy and birth as a positive experiences. However, the study is not consistence with the study conducted in Addis Ababa public hospitals; which shows there is no statistical significant association between perinatal mortality and ANC booking [AOR $=6.15$; 95\%Cl:0.31-122.04] (12) The difference might be due to difference in study setting.

With regard to duration of labour, mothers with prolonged labour (labour took $>=8 \mathrm{hr}$ ) were 2.75 times more likely for perinatal death than mothers had normal duration of labour ( $<$ labour took $<8 \mathrm{hr}$ ) [AOR = 2.75 ; $95 \% \mathrm{Cl}$ : (1.58-4.78), p-value<0.001]. The present finding is similar with the study conducted in Kenya that found prolonged labour was the main risk factor for perinatal mortality $[\mathrm{AOR}=7.9 ; 95 \% \mathrm{Cl}$ : 3.9215.94] (25). The result also supported by one study done in Ethiopia [(AOR $=8.79,95 \% \mathrm{Cl}(2.25-34.38)]$ (17). This might be due to prolonged labour increased risk of birth Aspasia, birth trauma, umbilical cord prolapse, PROM; which results increased perinatal mortality and morbidity (26)

Mothers who gave birth to low birth weight were 1.78 times more likely to have perinatal death as compared to those who gave birth to a normal birth weight baby [AOR $=1.78 ; 95 \% \mathrm{Cl}(1.06-2.97)$, p-value $=0.029]$. This finding is consistence with the result of other studies in Ethiopia and developing countries $(17,22,27)$ and showed that newborns who were low birth weight $(<2500 \mathrm{gm})$ were more likely for death compared to newborns with normal birth weight. This is due to the fact that being low birth weight is at high risk for hypothermia, which is one the cause PM.

Mothers who had complication during delivery were 2.15 times more likely of having perinatal mortality compared to those who had no complication [AOR $=2.15 ; 95 \% \mathrm{Cl}:(1.28-3.62)$, $\mathrm{p}$-value $=0.004]$. This result 
is in line with the result of other studies in Ethiopia and developing countries $(15,22,25)$ that showed obstetric complications were strongly associated with perinatal mortality.

The odds of perinatal mortality were $50 \%$ less likely among mothers whose labor was followed using partograph compared to their counter parts [AOR $=0.5 ; 95 \% \mathrm{Cl}: 0.25-0.9, \mathrm{P}$-value $=0.025]$. This finding is consistence with the study conducted in public hospitals of Addis Ababa [AOR $=0.35$; $95 \% \mathrm{Cl}$ : $(0.18-$ 0.66)] (12). This implies that using WHO recommended partograph is a protective factor for perinatal mortality. This might be due to use of partograph can help alert health care providers to pick any abnormalities during the course of labor. Therefore, it can prevent perinatal loss with early diagnosis and management of labor complications.

The odds of perinatal mortality were $48 \%$ less likely among mothers whose labor was followed using safe childhood checklist compared to their counter parts [AOR $=0.52 ; 95 \% \mathrm{Cl}: 0.30-0.91, \mathrm{P}$-value $=0.024]$. This might be due to the WHO safe childbirth checklist helps health-care workers ensure that essential birth practices are performed at critical moments during childbirth for every delivery, every time (27).

And mothers who came with referral to the hospital were 2.69 times more likely to end up in perinatal death as compared to mothers who came to hospital by themselves [(AOR $=2.69 ; 95 \% \mathrm{Cl}(1.51-4.8) ; \mathrm{p}$ value $=0.001]$. This might be related with coming with referral lead to delay on delivery care, miss's early $\mathrm{C} / \mathrm{S}$. Similarly, information obtained may have not been enough to assess due to the effect of this delay. This finding is consistence with other study conducted in Wolyta Sodo referral hospital [(AOR $=7.32$; $95 \% \mathrm{Cl}(2.47,21.63)](17)$.

\section{Limitation of the Study}

Since this study was conducted based on secondary data that was gathered for other purpose, it was difficult to gather all necessary variables. The confounding effect of unmeasured variables could not be controlled.

\section{Conclusion}

In conclusion, being rural in mother's place of residence, presence of obstetrics complication during delivery, duration of labour, low birth weight and coming with referral were positively associated with perinatal mortality; whereas antenatal care booking, using partograph, and using safe childbirth checklist were negatively associated with perinatal mortality. Therefore, managers should strictly monitor ambulance service utilization for minimizing delay during referral. Health care providers should give special attention for early recognition of abnormalities and manage accordingly while doing ANC and labor follow up. Similarly, they should do immediate newborn care with special attention to newborns with low birth weight. It will better if researchers conduct further longitudinal community based study to get other unmeasured risk factors. 


\section{Abbreviations}

ANC: Antenatal Care; AIDS: Acquired Immune Deficiencies Syndrome; C/S: Cesarean Section; END: Early Neonatal Death; EDHS: Ethiopian Demographic Health Survey; SNNPR: South Nations Nationality Population Representative; TGH: Tercha General Hospital; VDRL: Venereal Disease Research Laboratory; WHO: World Health Organization

\section{Declarations}

\section{Acknowledgements}

We would like to thank Jimma University Institute of Health for giving us this chance. We want to sincerely acknowledge Tercha general hospital staffs, data collectors, and supervisors for their cooperation.

\section{Funding}

This study was sponsored by Jimma University, Institute of Health. The funder of the study had no role in study design, data collection, data analysis, data interpretation, writing of the report and in writing the manuscript.

\section{Availability of data and materials}

The data supporting our findings are found at, kept in confidential and stored at the correspondent author both in hard and soft copies. If someone wants our data, we are voluntary to share it and the correspondent author should be contacted through the email address under the author's information

\section{Authors' Contributions}

FTD, developed the proposal, carried out data collection, conducted the analysis, involved in reviewing the manuscript and had full access to all the data in the study and had final responsibility for the decision to submit for publication. $\mathrm{CH}$ and MB provided general guidance in overall study progress and participated in reviewing the proposal, reviewing the analysis and participated in final study document development. AA participate in reviewing the whole document and guide the preparation of manuscript.All authors read and approved the final manuscript and accountable for all aspects of the work.

\section{Ethics approval and consent to participate}


Ethical clearance was obtained from Institutional Review Board (IRB) of Jimma University, Faculty of Public Health. Following the endorsement by the IRB, a written permission obtained from Tercha general hospital. Furthermore, confidentiality was assured throughout the process.

\section{Consent for publication}

Not applicable.

\section{Competing interests}

I declare that the study has no competing of interests.

\section{References}

1. World Health Organisation (WHO). Perinatal mortality rate. 2008. 2 p.

2. Gregory ECW. Fetal and Perinatal Mortality: United States: National Vital statistics reports. NCHS. 2015;64(8):1-24.

3. World Health Organisation (WHO). Neonatal and Perinatal Mortality Country, Regional and Global Estimates. 2006.

4. FMOH. Technical and Procedural Guidelines for Safe Abortion Services in Ethiopia. 2006.

5. Sugai MK, Gilmour S, Ota E, Shibuya K. Trends in perinatal mortality and its risk factors in Japan: Analysis of vital registration data, 1979-2010. Nat Publ Gr [Internet]. 2017;1-8. Available from: http://dx.doi.org/10.1038/srep46681

6. World Health Organisation (WHO). Making Every Baby Count: audit and review of stillbirths and neonatal deaths. 2016. $144 \mathrm{p}$.

7. Berhan Y, Berhan A. Systematic review perinatal mortality trends in ethiopia,1974-2013. Ethiop J Heal Sci. 2014;

8. WHO. Trends in Maternal Mortality: 1990 to 2010 [Internet]. Vol. 32. 2012. 1-55 p. Available from: http://whqlibdoc.who.int/publications/2010/9789241500265_eng.pdf

9. Ezechi OC, David AN. Overview of Global Perinatal Mortality. 2010. 1-11 p.

10. Still- L, More S. National, regional, and worldwide estimates of stillbirth rates in 2015, with trends from 2000: a systematic analysis. Matern Reprod Child Heal (MARCH. 2016;(15).

11. WHO. Neonatal mortality Situation and trends. In: Global health and obsrbatory data. 2017.

12. Getiye $Y$, Fantahun $M$. Factors associated with perinatal mortality among public health deliveries in Addis Ababa, Ethiopia, an unmatched case. BMC Pregnancy Childbirth. 2017;1-7.

13. FMOH. Ethiopia Demographic and health survrey. 2016.

14. FMOH. Ethiopia Demographic and Health Survey; Preliminary Report. 2011. 
15. Daniela SchoepsI Marcia, Marcia Furquim de Almeida GPAE. Risk factors for early neonatal. J IFaculdade Med. 2007;41(6).

16. Demise A, Gebrehiwot Y, Worku B, Spector JM. Prospective Audit of Avoidable Factors in Institutional Stillbirths and Early Neonatal Deaths at Tikur Anbessa Hospital in Addis. African J Reprod Heal December. 2015;19(December):78-86.

17. Mihiretu A, Negash T, Elazar T. Perinatal Death and Associated Factors in Wolaita Sodo Referral Hospital, Southern Ethiopia: a Facility Based Cross-Sectional Study. African J Reprod Heal December. 2017;7(2).

18. Mpembeni R. Perinatal Mortality and Associated Factors Among Deliveries in Three Municipal Hospitals of Dar Es Selaam. J Pediatr Neonatal Care Perinat. 2014;1(4):1-7.

19. Tercha General Hospital Annual Plan [Unpublished Document]. 2017.

20. Abduselam Mohammed, Kalkidan Hassen GMA. Assessment of Unmet Need in Emergency Obstetric Services in Tarcha General Hospital, Dawro Zone, South West Ethiopia. Heal scince jur. 2015;9(20).

21. Aragaw YA. Perinatal Mortality and associated Factor in Jimma University Specialized Hospital, South West Ethiopia. Gyneclo Obs. 2016;6(11):1-5.

22. Bayou G, Berhan Y. Perinatal mortality and associated risk factors: a case control study. Ethiop J Heal sci. 2009;22(3).

23. Ali A et al. Factors Associated with Perinatal Mortality in Kassala, Eastern Sudan. Jr Trop periatrics. 2014;60(1):79-82.

24. Yego F, Este CD, Byles J, Nyongesa P, Williams JS. A case-control study of risk factors for fetal and early neonatal deaths in a tertiary hospital in Kenya. BMC pregnancy childbirth Cit. 2014;14.

25. Weiner $\mathrm{R}$ et al. Labour complications remain the most important risk factors for perinatal mortality in rural Kenya. Bull World Health Organ. 2003;81(02):1-6.

26. FMOH. Managment Protocole On Selected ObstetricTtopics. 1st ed. Addis Ababa; 2010. 1-228 p.

27. WHO. Safe Childbirth Checklist Implementation Guide:Improving the quality of facility-based delivery for mothers and newborns. 2015.

\section{Tables}

Table 1: Socio demographic characteristics of mothers of perinatal deaths (cases) and controls among deliveries in Tercha general hospital, SNNPS, 2014-2017. 


\begin{tabular}{|c|c|c|c|c|}
\hline \multirow[t]{2}{*}{ Variables } & \multicolumn{2}{|c|}{ Cases } & \multirow{2}{*}{$\begin{array}{l}\text { Controls } \\
\text { №=183 }\end{array}$} & \multirow[b]{2}{*}{$\%$} \\
\hline & №=183 & $\%$ & & \\
\hline \multicolumn{5}{|l|}{ Age } \\
\hline$<20$ years & 30 & 16.3 & 43 & 23.46 \\
\hline 20-35 years & 135 & 73.7 & 121 & 66.2 \\
\hline$>35$ years & 18 & 10.0 & 19 & 10.3 \\
\hline \multicolumn{5}{|l|}{ Marital status(Mother) } \\
\hline Married & 153 & 83.6 & 153 & 83.6 \\
\hline Single & 16 & 8.74 & 15 & 8.74 \\
\hline Widowed & 8 & 4.37 & 8 & 4.3 \\
\hline Divorced & 6 & 6.28 & 7 & 3.83 \\
\hline \multicolumn{5}{|l|}{ Residency } \\
\hline Rural & 145 & 79.2 & 106 & 57.9 \\
\hline Urban & 38 & 20.8 & 77 & 42.1 \\
\hline \multicolumn{5}{|l|}{ Occupational Status } \\
\hline Housewife & 99 & 54.1 & 102 & 55.74 \\
\hline Gov't employed & 26 & 14.2 & 23 & 12.57 \\
\hline Student & 6 & 3.28 & 14 & 7.65 \\
\hline Self-employed & 52 & 28.4 & 44 & 24.04 \\
\hline \multicolumn{5}{|l|}{ Educational Status } \\
\hline No formal education & 87 & 47.54 & 64 & 34.97 \\
\hline Primary school & 43 & 23.50 & 66 & 36.07 \\
\hline Secondary school & 34 & 18.58 & 32 & 17.49 \\
\hline Diploma and above & 19 & 10.38 & 21 & 11.48 \\
\hline
\end{tabular}

Table 2: Obstetrics characteristics of mothers of perinatal deaths (cases) and controls among deliveries in Tercha general hospital, SNNPS, 2014-2017. 


\section{Variables}

Case

Control

№ $=183$

$\%$

№=183

$\%$

Parity

Primipara

62

$33.88 \quad 87$

48

Multipara

121

62.1296

62

Birth Interval

$>=2$ year

67

$36.6 \quad 62$

78.14

$<2$ year

52

$28.41 \quad 47$

21.86

TT vaccination

$>=2$ times

117

63.93143

78.14

$<2$ times

66

$36.07 \quad 40$

21.86

ANC booking

Yes

118

$64.48 \quad 146$

79.78

No

65

$35.52 \quad 37$

20.22

Mode of Delivery

SVD

95

$51.91 \quad 122$

66.67

Instrumental

30

16.3931

16.94

$\mathrm{C} / \mathrm{S}$

58

31.6930

16.39

History of abortion

Yes

28

$15.3 \quad 16$

8.74

No

155

$84.7 \quad 167$

91.26

History of previous perinatal mortality 
Yes

No

Duration of labour

$<8 \mathrm{hr}$

$>=8 \mathrm{hr}$

Presence of obstetrics complication

Yes

No

Preeclampsia

Yes

10

173

No

Antepartum hemorrhage

Yes

No

Uterine rupture

Yes

10

173

28

155

No

PROM

Yes

No

Obstructed labour

Yes
33

150
103

80

$23.5 \quad 86$

46.99

$76.5 \quad 97$

53.01

$56.28 \quad 51$

27.87

$43.72 \quad 132$

72.13

76.5

$81.97 \quad 166$

53.01

(


Table 3: Maternal medical, neonatal and organizational related factors of perinatal deaths (cases) and controls among deliveries in Tercha general hospital, SNNPS, 2014-2017. 


\begin{tabular}{llll}
\hline Variables & \multicolumn{2}{c}{ Cases } & \multicolumn{2}{c}{ Controls } \\
\cline { 2 - 3 } & №=183 & $\%$ & №=183
\end{tabular}

HIV test status

$\begin{array}{lllll}\text { Reactive } & 4 & 2.19 & 1 & 0.55 \\ \text { None reactive } & 162 & 88.5 & 180 & 83.1 \\ \text { Unknown } & 17 & 9.29 & 2 & 1.09\end{array}$

VDRL test status

$\begin{array}{lllll}\text { None reactive } & 177 & 96.7 & 181 & 98.9 \\ \text { Unknown } & 6 & 3.28 & 2 & 1.09\end{array}$

Hepatitis B test status

$\begin{array}{lllll}\text { Reactive } & 1 & 0.55 & 2 & 1.09 \\ \text { None reactive } & 150 & 82 & 160 & 87.4 \\ \text { Unknown } & 32 & 17.5 & 21 & 11.5\end{array}$

Hemoglobin level

$$
\begin{aligned}
& <11 \mathrm{gm} / \mathrm{dl} \\
& >=11 \mathrm{gm} / \mathrm{dl}
\end{aligned}
$$

140

$23.5 \quad 16$

8.74

$76.5 \quad 167$

91.3

History of chronic illness

Yes

$$
31
$$

$16.9 \quad 14$

7.65

No

152

$83.1 \quad 169$

92.3

Fetal presentation

Vertex presentation

107

58.47136

74.32

Mal presentation

76

$41.53 \quad 47$

25.68

Sex of newborn

Male

82

44.8198

53.55

Female

101

$55.19 \quad 85$

46.45

Wight of newborn

$<2500$ gm

78

$42.62 \quad 55$

30.05

$>=2500 \mathrm{gm}$

105

$57.38 \quad 128$

69.95

Congenital anomaly

Yes 
Table 4: Organizational related factors of perinatal deaths (cases) and controls among deliveries in Tercha general hospital, SNNPS, 2014-2017

\begin{tabular}{lllll}
\hline Variables & \multicolumn{2}{c}{ Cases } & \multicolumn{3}{c}{ Controls } \\
\cline { 2 - 4 } & №=183 & $\%$ & №=183 & \% \\
\hline Use of Partograph & 128 & 69.9 & 162 & 88.5 \\
Yes & 55 & 30.1 & 21 & 11.5 \\
No & & & & \\
Use of child birth checklist & 102 & 55.7 & 138 & 75.4 \\
Yes & 81 & 44.3 & 45 & 24.6 \\
No & & & & \\
Coming with referral & 72 & 39.3 & 28 & 15.3 \\
Yes & 111 & 60.7 & 155 & 84.7 \\
No & & & & \\
\hline
\end{tabular}

Table 5: The association between different factors and perinatal mortality in Tercha General Hospital, SNNPS, 2014-2017 


\begin{tabular}{|c|c|c|c|c|}
\hline \multirow[t]{2}{*}{ Categories } & \multicolumn{2}{|c|}{ Perinatal Outcome } & \multirow[t]{2}{*}{ COR(95\%CI) } & \multirow[t]{2}{*}{$\operatorname{AOR}(95 \% \mathrm{CI})$} \\
\hline & $\begin{array}{l}\text { Case № (\%) } \\
\text { (№=183) }\end{array}$ & $\begin{array}{l}\text { Control № (\%) } \\
\text { (№=183) }\end{array}$ & & \\
\hline \multicolumn{5}{|l|}{ Residence } \\
\hline Rural & $145(79.2)$ & $106(57.9)$ & $2.77(1.74,4.4)^{* *}$ & $1.8(1.4,3.19)^{* *}$ \\
\hline Urban & $38(20.8)$ & $77(42.1)$ & 1 & 1 \\
\hline \multicolumn{5}{|l|}{ Hemoglobin level } \\
\hline$<11 \mathrm{gm} / \mathrm{dl}$ & $43(23.5)$ & $16(8.74)$ & $3.2(1.73,5.9)^{* *}$ & $1.62(0.79,3.33)$ \\
\hline$>11 \mathrm{gm} / \mathrm{dl}$ & $140(76.5)$ & $167(91.3)$ & 1 & 1 \\
\hline \multicolumn{5}{|c|}{ History of chronic illness } \\
\hline Yes & $31(16.9)$ & $14(7.65)$ & $2.46(1.26,4.8)^{*}$ & $1.19(0.52,2.75)$ \\
\hline No & $152(83.1)$ & $169(92.3)$ & 1 & 1 \\
\hline \multicolumn{5}{|l|}{ Presentation } \\
\hline Vertex & $107(58.47)$ & $136(74.32)$ & 1 & 1 \\
\hline Mal presentation & $76(41.53)$ & $47(25.68)$ & $2(1.32,3.3)^{* *}$ & $1.23(0.67,2.26)$ \\
\hline \multicolumn{5}{|l|}{ Wight of newborn } \\
\hline$<2500 \mathrm{gm}$ & $78(42.62)$ & $55(30.05)$ & $1.73(1.12,2.6)^{*}$ & $1.7(1.06,2.9)^{* *}$ \\
\hline$>=2500 \mathrm{gm}$ & $105(57.38)$ & $128(69.95)$ & 1 & 1 \\
\hline \multicolumn{5}{|l|}{ Use of partograph } \\
\hline Yes & 128(69.9) & $162(88.5)$ & $0.3(0.17,0.52)^{* *}$ & $0.5(0.25,0.9)^{* *}$ \\
\hline No & $55(30.1)$ & $21(11.5)$ & 1 & 1 \\
\hline \multicolumn{5}{|c|}{ Use of childbirth checklist } \\
\hline Yes & $102(55.7)$ & $138(75.4)$ & $0.41(0.26,0.64)^{*}$ & $0.52(0.3,0.9)^{* *}$ \\
\hline No & $81(44.3)$ & $45(24.6)$ & 1 & 1 \\
\hline \multicolumn{5}{|c|}{ Coming with referral } \\
\hline Yes & $72(39.3)$ & $28(15.3)$ & $3.59(2.18,5.92)^{*}$ & $2.69(1.5,4.8)^{* *}$ \\
\hline No & $111(60.7)$ & $155(84.7)$ & 1 & 1 \\
\hline \multicolumn{5}{|l|}{ TT vaccination } \\
\hline$>=2$ times & $117(63.93)$ & $143(78.14)$ & $0.49(0.31,0.78)^{*}$ & $0.86(0.35,2.125)$ \\
\hline$<2$ times & $66(36.07)$ & $40(21.86)$ & 1 & 1 \\
\hline ANC Booking & & & & \\
\hline
\end{tabular}




\begin{tabular}{|l|l|l|l|l|} 
Yes & $118(64.48)$ & $146(79.78)$ & $0.46(0.29,0.73)^{* *}$ & $0.47(0.27,0.83)^{* *}$ \\
\hline No & $65(35.52)$ & $37(20.22)$ & 1 & 1 \\
\hline Mode of delivery & & & & \\
\hline SVD & $122(66.67)$ & $95(51.91)$ & 1 & 1 \\
\hline Instrumental & $31(16.94)$ & $30(16.39)$ & $1.24(0.7,2.9)$ & $0.94(0.42,2.11)$ \\
\hline C/S Previous & $58(31.69)$ & $30(16.39)$ & $2.24(1.48,4.15)^{*}$ & $1.059(0.47,2.35)$ \\
\hline $\begin{array}{l}\text { History of } \\
\text { perinatal mortality }\end{array}$ & & & & \\
\hline Yes & $33(18.03)$ & $17(9.29)$ & $2.1(1.15,4.02)^{*}$ & $1.28(0.62,2.63)$ \\
\hline No & $150(81.97)$ & $166(76.5)$ & 1 & 1 \\
\hline Duration of labour & & & & 1 \\
\hline$<8 h r$ & $43(23.5)$ & $86(46.99)$ & 1 & $2.75(1.6,4.78)^{* *}$ \\
\hline$>=8 h r$ & $140(76.5)$ & $97(53.01)$ & $2.89(1.8,4.5)^{* *}$ & \\
\hline Obstetrics complication & & & & 1 \\
\hline Yes & $103(56.28)$ & $51(27.87)$ & $3.3(2.16,5.15)^{* *}$ & $2.2(1.28,3.62)^{* *}$ \\
\hline No & $80(43.72)$ & $132(72.13)$ & 1 & 1 \\
\hline
\end{tabular}

Note: $* \mathrm{p}<0.25, \quad * * \mathrm{p}<0.05 \quad$ (Indicates statistically significant) 